\title{
ALGAS: DA ECONOMIA NOS AMBIENTES AQUÁTICOS À BIOREMEDIAÇÃO E À QUÍMICA ANALÍTICA
}

Eliane Cristina Vidotti e Maria do Carmo E. Rollemberg*

Departamento de Química, Universidade Estadual de Maringá, Av. Colombo, 5790, 87020-900 Maringá - PR

Recebido em 24/10/02; aceito em 11/7/03

\begin{abstract}
ALGAE: FROM AQUATIC ENVIRONMENT ECONOMY TO BIOREMEDIATION AND ANALYTICAL CHEMISTRY. Algae constitute a large group of many different organisms, essentially aquatic and able to live in all systems giving them sufficient light and humidity. Some algae species have been used in the evaluation or in the bioremediation of aquatic systems. More recently algae have been suggested as interesting tools in the field of analytical chemistry. In this work the most important aspects related to the different uses of algae are presented with a brief discussion.
\end{abstract}

Keywords: algae; bioremediation; analytical chemistry.

\section{INTRODUÇÃO ou o que são algas?}

Vivemos em um planeta coberto por grandes extensões de águas, doces ou marinhas, cuja herança obriga-nos a preservar. Nesta imensa "solução" destacamos a diversidade de organismos, de certa forma relacionada à diversidade das comunidades de algas. Cabe a estas a estabilidade dos ecossistemas naturais, pois um maior número de espécies equivalentes funcionalmente, mas com diferentes capacidades de tolerância aos inúmeros fatores ambientais, resiste melhor a alterações no meio aquático, inclusive a alterações decorrentes da atividade humana. Neste contexto, pela importância que o tema apresenta sob a ótica econômica neste novo milênio, e sendo o Brasil um país-continente rico em recursos aquáticos, apresentamos alguns aspectos relacionados às algas. Neste artigo, as interações entre algas e o ambiente, o uso destes organismos com o objetivo de restabelecer sistemas aquáticos, as aplicações nos processos de biorremediação e na Química analítica, além dos usos industriais das algas são destacados. Certamente, muitos outros deixarão de ser mencionados, mas propomos o despertar de interesses pelo estudo destes organismos, sob suas múltiplas possibilidades.

Ao longo de todo a sua existência o homem sempre manteve relações próximas com o imenso mundo vivo, mas apenas a partir do século XX tornou-se possível identificar e classificar os principais grupos de seres vivos existentes. Na Grécia antiga, rica em pensadores e naturalistas, houve uma primeira tentativa de reunir os seres vivos segundo as semelhanças que apresentavam entre si, sendo reconhecidos os grupos animal e vegetal. Mas foi com Charles Darwin (1809-1882) que o sistema de classificação dos seres vivos ganhou um enfoque evolutivo e as espécies passaram a ser classificadas de acordo com a origem ou a ancestralidade comum, isto é, refletindo relações evolutivas. Em 1969 R. H. Whittaker propôs um sistema de classificação das espécies em cinco reinos.

As algas são consideradas em três diferentes reinos: monera, protista e plantae. As algas azuis ou cianobactérias, organismos do reino monera, são unicelulares, procariontes (ausência de envoltório nuclear) e autótrofos (produzem seu próprio alimento); habitam vários ambientes, desde que haja umidade, e atuam como "espécies pioneiras" por sua pequena exigência nutricional, capacidade de realizar fotossíntese e aproveitar o nitrogênio atmosférico.

\footnotetext{
*e-mail: mcerollemberg@uem.br
}

Os organismos do reino protista são unicelulares (embora existam formas pluricelulares de organização simples), autótrofos ou heterótrofos (dependem de outros seres para se alimentarem), e suas células apresentam envoltório nuclear e organelas membranosas (organismos eucariontes); são organismos de grande simplicidade e constituem o primeiro grupo onde ocorrem mitocôndrias, cloroplastos, retículo endoplasmático e complexo de Golgi bem desenvolvidos, apresentando, em geral, um único núcleo. As algas pertencentes ao reino protista apresentam pigmentos - clorofilas, carotenos e xantofilas - organizados em organelas denominadas plastos, que permitem a fotossíntese. Suas principais características podem assim ser apresentadas:

- Filo Euglenophyta, composto por organismos denominados euglenas, presentes quase que exclusivamente em águas doces; possuem uma única célula com uma película externa de constituição protéica. As euglenas podem ser heterótrofas ou autótrofas e estas apresentam muitos plastos contendo clorofilas a e b e carotenos, e armazenam óleos e polissacarídeos como reserva.

- Filo Pyrrophyta, composto pelos organismos dinoflagelados (apresentam dois flagelos dispostos em sulcos perpendiculares), fitoplanctônicos e predominantemente marinhos. São organismos autótrofos que apresentam clorofilas a e c, caroteno e peridinina (pigmento exclusivo do grupo), e armazenam amidos e óleos como substâncias de reserva; a presença de carotenos e de peridinina confere a tonalidade amarelada aos dinoflagelados. A reprodução exagerada de dinoflagelados no mar pode levar ao fenômeno conhecido como maré vermelha, denominação esta relacionada à mudança da cor da superfície do mar, que se torna amarela ou laranja; a superpopulação de dinoflagelados consome grande parte dos nutrientes disponíveis e libera toxinas na água, capazes de envenenar ou matar outros animais.

- Filo Chrysophyta, composto pelas algas douradas e organismos denominados diatomáceas; vivem em ambientes aquáticos marinhos ou de água doce, participando da composição do fitoplâncton ou aderidas a um substrato em águas pouco profundas. São organismos autótrofos que apresentam clorofilas a e c, caroteno e xantofilas, armazenando óleos como reserva. As diatomáceas são revestidas por uma parede celular formada por sílica e, ao morrerem, contribuem para a formação do sedimento denominado "terra de diatomáceas", utilizado em indústrias.

No reino plantae são encontrados organismos pluricelulares, eucariontes e autótrofos, cujas principais características são: 
- Filo Chlorophyta, composto pelas algas verdes, extremamente abundantes nos ambientes aquáticos, onde é um dos mais importantes componentes do fitoplâncton; as algas verdes são responsáveis pela maior parte da produção de oxigênio molecular disponível no planeta a partir da fotossíntese. Habitando águas doces ou salgadas, solos úmidos ou troncos, estes organismos podem também estabelecer relações de mutualismo com outros seres vivos, como os fungos, formando os liquens. As algas verdes acumulam amido no interior de suas células, e contêm os pigmentos clorofilas a e b, carotenos e xantofilas; a presença de clorofilas a e b sustenta a idéia de que as algas verdes tenham sido as ancestrais das plantas, por serem estas possuidoras destes tipos de clorofila.

- Filo Rhodophyta, composto pelas algas vermelhas, quase que exclusivamente pluricelulares e marinhas (mais comuns em mares quentes), que vivem fixadas em um substrato; a principal característica é a presença do pigmento ficoeritrina em suas células, responsável pela coloração avermelhada destes organismos. As algas vermelhas possuem clorofilas a e d e carotenóides, e armazenam amido como material de reserva.

- Filo Phaeophyta, composto pelas algas pardas, organismos pluricelulares predominantemente marinhos (mais comuns em mares frios), vivendo fixados em um substrato ou flutuando, formando imensas florestas submersas. As algas pardas são as maiores existentes, podendo atingir mais de $25 \mathrm{~m}$. Nestes organismos são encontrados os pigmentos fucoxantina, clorofilas a e c e carotenóides e, como substâncias de reserva, óleos e polissacarídeo (laminarina).

As algas são organismos capazes de ocupar todos os meios que lhes ofereçam luz e umidade suficientes, temporárias ou permanentes; assim, são encontradas em águas doces, na água do mar, sobre os solos úmidos ou mesmo sobre a neve. Quer sejam uni ou pluricelulares, as algas retiram todos os nutrientes que precisam do meio onde estão - solução ou umidade - e, portanto, são organismos fundamentalmente aquáticos. Entretanto, apesar da simplicidade aparente destes organismos, algumas algas possuem "sistemas" internos que só são encontrados nos vegetais superiores" ${ }^{1}$ !

Algumas espécies de algas encontram uso na avaliação da qualidade dos sistemas aquáticos, para os quais, inclusive, já foi sugerido um "índice de poluição" baseado nos gêneros de algas presentes: quanto menos diversificada a população, maior a poluição do siste$\mathrm{ma}^{2}$. Um outro aspecto está relacionado à capacidade em retirar do meio aquoso elementos químicos, o que sugere a utilização de algumas espécies de algas na recuperação de sistemas aquáticos, em especial quanto à presença de íons metálicos e de alguns compostos orgânicos. Finalmente, mais recentemente tem sido avaliado o uso das algas como "reagentes químicos", em processos de pré-concentração na química analítica.

Nos sistemas aquáticos as algas incorporam energia solar em biomassa, produzem o oxigênio que é dissolvido na água e usado pelos demais organismos aquáticos, atuam na mineralização e no ciclo dos elementos químicos, e servem como alimento para animais herbívoros e onívoros. Ao morrerem, seus constituintes químicos sofrem transformações nos sedimentos, são solubilizados e reciclados na água. Estas diferentes "funções" desempenhadas pelas algas nos sistemas aquáticos dependem da temperatura, da intensidade da radiação solar, da concentração de nutrientes na água e da alimentação dos animais presentes no sistema. As alterações naturais ou antropogênicas no sistema aquático podem alterar o balanço destes fatores controladores, e causar mudanças na composição da comunidade de algas, nas taxas de produtividade, na biomassa e na química da água. É importante perceber que, tanto a inibição como a estimulação do crescimento dos organismos, são igualmente indesejá- veis, pois qualquer alteração na produtividade das algas ou na composição da comunidade, em relação ao usual para aquele sistema em particular, pode ameaçar todo o equilíbrio do ecossistema ${ }^{3}$.

Como espécies representativas do nível trófico inferior, as algas são organismos ecologicamente importantes, porque servem como fonte de alimento fundamental para outras espécies aquáticas e ocupam, assim, uma posição única entre os produtores primários: são um elo importante na cadeia alimentar e essenciais à "economia" dos ambientes aquáticos como alimento.

Assim como os outros vegetais aquáticos e terrestres, pouco ou muito evoluídos, as algas necessitam de água, luz, gás carbônico e minerais para o crescimento e a manutenção da vida. Cada organismo possui um modo especial de atender às suas necessidades, mas, apesar da grande variação de cor, tamanho, forma e tipo de reprodução, todas as algas têm em comum o fato de produzirem seu próprio alimento através da fotossíntese, pois todas possuem clorofila. As algas retiram do meio o que necessitam através de toda a superfície do "corpo" e, portanto, não necessitam de tecidos especiais para transporte dos nutrientes no interior das suas células. Mas a vida no ambiente aquático apresenta algumas dificuldades, como a penetração da luz, já que a partir de uma certa profundidade não há luz suficiente para a fotossíntese; a escassez de minerais, tornando o meio muitas vezes limitante em relação a um mineral; ou ainda a presença do gás carbônico, que não circula de modo tão simples quanto na atmosfera ${ }^{4}$.

A VIDA EM SOCIEDADE ou as relações entre algas e ambiente

Os organismos aquáticos influenciam a concentração de muitas substâncias diretamente por captação metabólica, transformação, armazenamento e liberação sendo, portanto, importante conhecer a interação entre os organismos e o ambiente para melhor compreensão da química de um habitat aquático. Os processos primordiais são a fotossíntese e a respiração; como resultado da fotossíntese são produzidas ligações ricas em energia, que alteram o equilíbrio termodinâmico. Pela respiração são catalisados processos redox e o equilíbrio é restaurado. O balanço entre fotossíntese e respiração é responsável pelo controle da concentração de oxigênio na água e estes dois processos são importantes na purificação das águas naturais; distúrbios temporais ou localizados deste estado estacionário levam a alterações biológicas e químicas que refletem poluição ${ }^{5}$.

As comunidades de algas são controladas por muitos fatores ambientais, bióticos e abióticos, os quais podem, por sua vez, ser afetados por espécies químicas estranhas ao meio (contaminantes), produzindo mudanças na estrutura e no funcionamento da comunidade. As algas podem sofrer efeitos diretos, em curtos tempos, e também, efeitos indiretos, sendo estes resultantes dos efeitos diretos sobre outros organismos no meio. Alguns exemplos podem ser apresentados, evidenciando a íntima relação entre uma comunidade de algas e o ambiente em que se encontram.

$>$ Interações algas - macrófitas: há muita discussão sobre o papel das macrófitas (espécies de vegetais adaptados ao ambiente aquático ao longo do seu processo evolutivo), mas uma hipótese parece ser que elas absorvem $\mathrm{N}$ e $\mathrm{P}$ inorgânicos dissolvidos, competindo com as algas pelos nutrientes. O impacto direto dos contaminantes sobre as macrófitas pode produzir efeitos diversos sobre a comunidade de algas. A morte das macrófitas pode, em certas condições, potencializar um aumento dos nutrientes inorgânicos no sistema, mas estudos realizados com herbicidas ${ }^{6}$ (eliminando as macrófitas) indicaram que este aumento nas quantidades de nitrogênio e de fósforo disponíveis para as algas só ocorre após uma grave desoxigenação da água. Outros estudos mostraram que, com o aumento do nível de iluminação, associa- 
do ao aumento nos níveis de nutrientes, pode ocorrer um crescimento da população de algas ${ }^{6}$.

$>$ Interações algas - zooplancton: as algas são o alimento principal para os invertebrados aquáticos, e isso pode afetar a população de duas maneiras distintas: uma taxa de alimentação moderada pode estimular o crescimento e a produção de algas, aumentando a velocidade de reciclagem de nutrientes; uma "grande" taxa de alimentação reduz a abundância de algas.

> Interações algas - substâncias orgânicas: compostos organoclorados agem diretamente sobre as algas inibindo a fotossíntese; compostos organofosforados são ainda mais tóxicos na inibição da fotossíntese das algas, mas, sendo menos persistentes no ambiente, não representam uma ameaça crônica para as comunidades de algas, a menos que continuamente introduzidos no sistema aquático. Herbicidas diminuem a biossíntese de lipídeos nas algas - e os lipídeos são elementos estruturais da membrana celular e de várias organelas, controlando o movimento de substâncias para o interior das células.

$>$ Interações algas - íons metálicos: íons de metais divalentes $(\mathrm{Cu}$, $\mathrm{Cd}, \mathrm{Hg}, \mathrm{Pb}, \mathrm{Zn}, . .$.$) podem reduzir a fotossíntese causando dano$ estrutural aos cloroplastos; quantidades traços de cobre, por exemplo, acima da capacidade de complexação do meio, inibem por completo a fixação de $\mathrm{N}$, reduzindo o processo de eutrofização. Entretanto, este processo torna-se favorecido devido ao aumento do consumo de oxigênio decorrente da biodegradação das algas mortas.

$>$ Interações algas - luz: o fitoplancton necessita da energia solar para a fotossíntese; entretanto, muitas espécies não toleram níveis mais elevados de luz (UV ou VIS), sendo rapidamente afetadas pela ação da radiação e, a fim de evitar o excesso de radiação, algumas espécies migram na coluna d'água ${ }^{6}$.

Estas interações, que variam entre espécies diferentes, podem resultar em mudanças nas espécies dominantes de algas em um sistema aquático particular, afetando todo o ecossistema. Experimentando essa íntima interação com o ambiente que lhes mantém a vida e no qual exercem funções decisivas, as algas surgem como elementos-chaves nos estudos ambientais. A diversidade de organismos em um sistema aquático está relacionada à diversidade das comunidades de algas, a qual favorece a estabilidade do ecossistema já que um maior número de espécies funcionalmente equivalentes, mas com capacidades de tolerância a fatores ambientais diferentes, resiste melhor às alterações do meio, inclusive aquelas causadas pela atividade humana ${ }^{7}$.

“QUEBRA - NOZES” ou as algas como indicadores biológicos

Deus nos deu as nozes - mas nós temos que quebrá-las...

Uma das principais finalidades da ecotoxicologia é avaliar os riscos ecológicos o que, pela complexidade e diversidade dos sistemas naturais, é ainda uma tarefa difícil. Um novo paradigma e também desafio da ecotoxicologia é a identificação de "alvos ecológicos" - elementos ou sinais-chaves que traduzam os processos de controle e suas alterações no ecossistema em risco. Embora estes "alvos" possam diferir entre os ecossistemas, uma vez identificados, a condição de normalidade pode ser avaliada por qualquer tipo de resposta biológica, seja ao nível bioquímico celular, orgânico, de populações ou de comunidades. Um outro paradigma é a mudança na abordagem dos problemas ecológicos, que antes visavam reparar danos e/ou restaurar vida - abordagem reativa, e hoje visam, sobretudo, proteger/preservar o ecossistema - abordagem pró-ativa. Nesta ótica de preservação, e por estarem relacionados às respostas primárias das células aos impactos recebidos do meio, os biomarcadores (bioquímicos e fisiológicos) são vistos como instrumentos eficientes de prevenção, desde que as alterações bioquímicas, fisiológicas ou comportamentais sejam respostas ainda não observáveis no nível orgânico - caso contrário, a sobrevivência do organismo, ou da população inteira, pode já estar comprometida. A alteração ou a erradicação das comunidades de plantas aquáticas pode resultar em habitats modificados que, em último grau, podem gerar um impacto maior nos níveis tróficos superiores que os efeitos em si das substâncias potencialmente tóxicas ${ }^{8}$.

A utilidade das algas como organismos testes tem por base seu ciclo de vida curto, facilitando os estudos de exposição com várias gerações, além das altas taxas de crescimento, da facilidade em manter culturas e da capacidade de crescer em meios sintéticos bem definidos. A origem dos bioensaios com algas é atribuída ao trabalho do Prof. Martinus Beijerinck (1890), primeiro a obter uma cultura pura de algas - imprescindível para os métodos de bioensaios. Desde então, grandes avanços têm ocorrido no desenvolvimento de meios de cultura apropriados, de métodos de isolamento e cultura das espécies, bem como na elaboração de modelos. Os ensaios com algas são fonte de informações quantitativas importantes sobre a disponibilidade das substâncias químicas, nutrientes ou substâncias potencialmente tóxicas e seus efeitos nos ecossistemas. É interessante observar que a informação total obtida nos ensaios com algas supera o significado da soma de todos os dados parciais sobre a abundância relativa dos componentes individuais do sistema aquático, uma vez que a análise química informa a concentração das substâncias presentes, mas não fornece conhecimento de sua influência na água, meio de crescimento para os diferentes organismos. Os ensaios com algas abrem a possibilidade de uma combinação de medidas físicas, químicas e biológicas, que resulta em informações importantes. Foi sugerido que, a partir de testes de toxicidade com algas, as substâncias químicas fossem classificadas quanto à sua toxicidade ambiental, auxiliando na avaliação do risco ambiental para os sistemas naturais ${ }^{2}$.

É importante perceber que a aplicação das algas como indicadores ecológicos é diversificada, tanto em tipo de habitat, quanto em parâmetros ecológicos e nenhum bioensaio simples, sozinho, pode ser usado como padrão, uma vez que cada situação real apresenta seus próprios problemas individuais (parece claro que testes padronizados para águas doces não se apliquem à água do mar, ou que conclusões obtidas em culturas de laboratório, em meio simples, não sejam extrapoladas para testes in situ...).

As algas são diretamente afetadas pelos efluentes químicos ou domésticos, contendo os nutrientes principais $\mathrm{N}$ e $\mathrm{P}$; na presença de excesso desses nutrientes, ocorre um rápido crescimento e multiplicação e, nestas condições, pode haver um deslocamento da população, dominação por uma(s) espécie(s) e/ou floração de algas, condições estas que indicam deterioração na qualidade da água. Os ensaios com algas são, então, úteis na determinação da disponibilidade biológica de $\mathrm{N}$ e $\mathrm{P}$, na avaliação da sensibilidade a mudanças na carga de $\mathrm{N}$ e $\mathrm{P}$, e na avaliação do impacto ambiental das descargas de efluentes ${ }^{8}$.

Os testes com algas permitem identificar materiais que afetam o crescimento, avaliar a disponibilidade biológica de nutrientes e determinar curvas dose-resposta para as substâncias limitantes do crescimento. Monoculturas crescidas em condições específicas de laboratório são usadas nestes estudos; exposições de curta duração podem ser usadas e, pelo curto ciclo de vida, estes testes podem ser considerados como de exposição crônica, podendo avaliar os efeitos sobre várias gerações. Diversos efeitos podem ser observados nas condições experimentais utilizadas, desde a estimulação até a inibição e assim, o significado ecológico de um teste com algas é demonstrado pela continuação da resposta após a remoção da substân- 
cia potencialmente tóxica. Bioensaios que avaliam o crescimento populacional após a exposição da alga a determinado poluente durante alguns dias, ou a inibição da fotossíntese após um breve contato não são suficientes para avaliar a adaptação biológica, e só uma resposta a longo prazo pode ser ecologicamente realista para recomendar medidas protetoras. Isto é, no lugar da preocupação quanto à natureza mecânica da adaptação, é mais importante conhecer até que ponto a adaptação pode alterar o fitoplancton como alimento para os níveis superiores. A tolerância apresentada por algumas espécies de algas a concentrações mais elevadas de algumas substâncias potencialmente tóxicas é bastante significativa para a acumulação na alga e para o comprometimento da cadeia alimentar pela transferência aos níveis tróficos superiores.

Alguns exemplos do uso de espécies de algas como bioindicadores no Brasil podem ser apresentados':

$>$ amostras da água da bacia da Pampulha, Belo Horizonte, MG, foram avaliadas frente a alga Selenastrum capricornutum, com testes de 96 h de exposição; os estudos realizados pelo Centro de Recursos Hídricos e Ecologia Aplicada da Escola de Engenharia de São Carlos - USP mostraram efeito de inibição do crescimento da biomassa em relação ao controle, indicando toxicidade da água à esta espécie em todos os pontos de amostragem (principais tributários da lagoa da Pampulha, responsáveis pela entrada de efluentes industriais, e na própria lagoa). Apenas um dos pontos de amostragem, próximo ao aterro sanitário de $\mathrm{BH}$ apresentou toxicidade aguda para Daphnia similis (organismo também utilizado como bioindicador), com $100 \%$ de mortalidade.

$>$ Culturas de diferentes espécies em amostras de águas da Baía da Guanabara, RJ, mostraram uma significativa redução nas taxas de crescimento das algas; a predominância das espécies Ulva fasciata e Enteromorpha compressa, indicadoras de poluição orgânica, foi observada no inventário da flora de algas na praia da Boa Viagem, Niterói, RJ. Os resultados apontaram uma profunda alteração nas comunidades de algas da Baía ao longo das últimas três décadas, em decorrência dos efeitos deletérios da sua água. Esse trabalho desenvolvido pela UFRJ, com apoio do Fundo Mundial para Natureza, serve como fonte de dados no monitoramento da recuperação da Baía.

$>$ Amostras de água e água intersticial de sedimento de diferentes pontos de amostragem do Reservatório de Salto Grande, Americana, SP, foram avaliados pelo Centro de Recursos Hídricos e Ecologia Aplicada da Escola de Engenharia de São Carlos - USP quanto à toxicidade frente à alga Selenastrum capricornutum, sendo o crescimento obtido após 96 h de exposição o parâmetro utilizado; os resultados indicaram um efeito tóxico agudo nas condições de teste para o organismo considerado.

Apesar dos resultados positivos evidenciados nos estudos realizados, e anteriormente citados, não são ainda encontrados na literatura trabalhos desenvolvidos nesta área da pesquisa com algas. Os testes de toxicidade envolvendo algas, sob diferentes condições físicas, químicas e biológicas, devem ainda ser melhorados em muitas áreas, com o objetivo de se desenvolver métodos mais sensíveis, de baixo custo, ecologicamente realistas e exequiíveis na prática, o que possibilitará uma melhor avaliação dos riscos de substâncias potencialmente tóxicas, nas comunidades de algas nos sistemas aquáticos. Estes testes poderão ser utilizados como ferramentas para definir zonas de impacto de rejeitos industriais, bem como identificar resíduos ambientais ou, ainda, auxiliar no desenvolvimento de produtos/processos com o objetivo de evitar a contaminação ambiental.

Deus nos deu as nozes - mas nós temos que quebrá-las: o uso experimental de culturas de algas oferece excelente auxílio para "quebrar" os problemas relacionados à interação entre biota e ambiente nas águas naturais. A atividade humana crescente e os problemas ambientais dela resultantes estão fornecendo muitas "nozes para quebrar", e o uso das algas mostra-as como eficazes "quebra-nozes"...

Os dois pesos de uma mesma medida ou bioacumulação e bioremediação

A distribuição dos elementos químicos apresenta peculiaridades nos sistemas biológicos já que estes, claramente, concentram alguns elementos, enquanto rejeitam outros, e alguns desses processos são acompanhados de variação de energia. Entretanto, havendo ou não envolvimento de energia, sítios de seletividade são necessários em algumas etapas da captação, e esta seletividade deve ser tratada independentemente de um controle cinético (energia envolvida). Ou seja, a biologia observa regras que são convencionais na análise inorgânica: evitar interferência de um segundo elemento, considerar as concentrações relativas e as constantes de ligação dos íons livres nos meios considerados. Os sistemas biológicos devem ter, portanto, uma variedade de ligantes, em diferentes "regiões do corpo", para concentrar e separar elementos inorgânicos ${ }^{10}$.

Bioacumulação é o nome genérico do processo de captação e retenção de uma substância (contaminante) por um organismo a partir de qualquer fonte (água, sedimento, outro organismo), via qualquer rota (dieta, pele), e se constitui em efeito nocivo quando induz resposta biológica adversa. O termo bioacumulação tem sido aplicado quando organismos vivos estão envolvidos, e biosorção é o termo mais adotado para o uso de organismos mortos ${ }^{11}$.

O processo de bioacumulação varia grandemente entre os diferentes organismos, e é particularmente importante nos níveis tróficos inferiores; devido a processos metabólicos e à alimentação, resulta em enormes fatores de concentração. Os invertebrados têm uma capacidade particularmente alta de concentrar metais e outros materiais encontrados no seu ambiente ao filtrarem o plâncton, durante a alimentação. Como os metais podem formar complexos estáveis com compostos orgânicos, há uma tendência em serem fixados nos tecidos, e não excretados, o que se traduz em elevada meia vida biológica - e isto talvez seja um dos maiores problemas apresentados pelos metais com relação aos seus efeitos sobre os organismos aquáticos, associado à transferência na cadeia alimentar. Alguns grandes "acidentes" ecológicos decorreram de processos de bioacumulação - Hg acumulado em peixes em Minamata (Japão) e a doença de Itai-itai, identificada como conseqüência da introdução de $\mathrm{Cd}$ na água, e acumulada nas espécies comestíveis (Japão).

A bioacumulação por algas desempenha três funções de importância ecológica significativa:

$>$ nos organismos, a bioacumulação reflete-se na alteração da concentração do contaminante no seu sítio de ação. Assim, a extensão com que ocorre a bioacumulação em um organismo (avaliada por meio da determinação do nível do contaminante no organismo) pode ser utilizada como um parâmetro útil em uma avaliação ecotoxicológica dos sistemas naturais.

> A bioacumulação de uma substância potencialmente tóxica pode torná-la, ao menos temporariamente, indisponível para outros organismos; ao ocorrer a acumulação de uma espécie contaminante por um determinado organismo (p. ex. algas), este contaminante torna-se presente no sistema aquático em menor concentração; portanto, para os demais organismos (p. ex. peixes, invertebrados) a ocorrência da bioacumulação pelas algas implica em maior resistência ao impacto tóxico. Nesta ótica, as algas podem ser consideradas "espécies protetoras" no ambiente aquático, pois contribuem para diminuir a fração do contaminante "disponível" para os demais organismos. É importante observar que a toxicidade de uma substância está relacionada a vários fatores, como organismos expostos, concentração da substância 
no meio e tempo de exposição; assim, uma substância tóxica em determinadas condições, pode não ser em condições distintas e, por esta razão, fala-se de substância potencialmente tóxica.

$>$ A bioacumulação de compostos orgânicos persistentes ou de metais pode ser um fator importante no transporte físico da substância potencialmente tóxica e na acumulação na cadeia alimentar pelos organismos consumidores superiores - onde inclui-se o homem ${ }^{12}$. A biomagnificação, processo pelo qual espécies potencialmente tóxicas são introduzidas nos organismos superiores, resultando na sua acumulação, é um outro aspecto importante nos estudos ecotoxicológicos.

Apesar de já ter sido mostrado o grande potencial a ser explorado quanto à capacidade das algas de "limpar" os sistemas aquáticos (especialmente porque os meios convencionais físicos e químicos de remoção de poluentes dissolvidos são, em geral, dispendiosos se aplicados na remoção de espécies em pequenas concentrações), este processo, denominado bioremediação, apenas há pouco tempo passou a ser considerado de fato ${ }^{13-16}$. A bioremediação vem evoluindo como uma tecnologia efetiva para o tratamento e a remoção de contaminantes de natureza inorgânica ${ }^{17-20}$ ou orgânica ${ }^{21,22}$. A avaliação de águas contaminadas com poluentes orgânicos, utilizando filamentos de cianobactérias, por exemplo, mostrou a habilidade natural destes microrganismos na degradação de pesticidas alifáticos clorados e de outros poluentes ${ }^{23}$. O uso das algas na recuperação de efluentes contendo espécies metálicas apresenta vantagens, como o baixo custo da operação e a elevada eficiência na remoção dos contaminantes de efluentes muito diluídos, mas é necessário conhecer o comportamento do microorganismo particular, as características do sistema aquático e da interação contaminante - alga para avaliar a eficácia do seu uso como ferramenta na recuperação do ecossistema. A avaliação do processo de bioremediação obedece a alguns critérios e, primeiramente, é preciso considerar a eficiência da remoção da(s) espécie(s) metálica(s). A possibilidade de recuperar o metal de forma economicamente viável e ecologicamente aceitável, sem resíduos indesejáveis, é um outro aspecto importante. Finalmente, deve ser considerada a rapidez de todo o processo de remediação do sistema aquático ${ }^{24,25}$.

As ferramentas analíticas ou o uso das algas na Química Analítica de metais traços

A captação de íons metálicos pelas algas decorre da ligação dos íons aos diferentes grupos funcionais das células dos organismos. A interação de superfície alga - íon metálico pode ser generalizada pela equação:

$\equiv \mathrm{SH}+\mathrm{M}^{\mathrm{m}+} \Leftrightarrow \equiv \mathrm{SM}^{(\mathrm{m}-1)+}+\mathrm{H}^{+}(\equiv \mathrm{S}$ : grupo ligante de superfície $)$

Williams ${ }^{26}$ e Wood e Wang ${ }^{27}$ desenvolveram modelos para a interação íon metálico - alga de qualquer processo biótico, onde a superfície dos organismos desempenha um papel predominante nas ligações aos metais. As algas interagem com os íons presentes em solução através de processos que compreendem dois estágios. O primeiro é provavelmente passivo, envolve adsorção ou troca iônica na superfície celular e ocorre pouco tempo depois do contato entre o organismo e o íon metálico; a etapa seguinte é ativa, lenta e relacionada à atividade metabólica. Organismos vivos ou mortos podem captar íons metálicos em solução, mas não havendo atividade biológica para as células mortas, a captação ocorre independentemente do metabolismo e só a etapa inicial, envolvendo processos de superfície, deve ser considerada. Na parede celular encontram-se os principais sítios de captação, os quais incluem amina, amida, imidazol, hidróxido, carboxilato, fosfato, tiol, tioéter, entre outros ${ }^{28,29}$.
Gardea-Torresdey e colaboradores estudaram cinco espécies de algas e monitoraram a adsorção de metais antes e depois da esterificação dos grupos carboxílicos. Os resultados sugerem que os grupos carboxílicos estão envolvidos na captação de íons $\mathrm{Cu}$ e $\mathrm{Al}$, mas não são responsáveis pela retenção de $\mathrm{Au}^{30}$.

A capacidade demonstrada pelas algas de diferentes espécies de captar e acumular íons metálicos depende do organismo propriamente dito e das espécies metálicas consideradas; entretanto, é importante observar que as superfícies das células das algas apresentam, em geral, grande afinidade pelos íons metálicos, mesmo na presença de quantidades bem maiores de íons cálcio ou magnésio espécies estas bastante comuns em águas naturais. O desempenho das algas como sorventes biológicos depende, ainda, da quantidade de biomassa, do pH da solução e da cinética da reação, além de outros fatores, como a competição pelos sítios de ligação $0^{31-33}$.

Esta elevada afinidade apresentada pelas algas em relação aos íons de diferentes metais, aliada ao baixo custo da produção da biomassa, despertou o interesse do seu uso em Química Analítica de elementos traços. Diversos procedimentos analíticos envolvendo a pré-concentração de íons metálicos de soluções aquosas têm sido avaliados e propostos, utilizando microorganismos livres ou imobilizados como material sorvente. Nestes casos, as células vivas podem ser utilizadas em diferentes métodos.

Um procedimento geral requer a mistura de uma solução analítica contendo íons metálicos com uma massa de 5 a 10 mg de microorganismos, agitação e separação do sobrenadante, seguida da determinação, que inclui ou não uma etapa de dessorção; em geral, utiliza-se a espectrometria de absorção atômica na determinação dos íons metálicos de interesse $\mathrm{e}^{34-37}$.

Holcombe e colaboradores descreveram uma série de estudos para pré-concentrar quantidades ultra-traços de $\mathrm{Cd}, \mathrm{Cu}$, Co e Ni usando biomassas de algas (Stichococcus-bacillares) liofilizadas, sendo alcançada elevada eficiência. Uma vantagem no uso das algas em processo de pré-concentração é que a presença de íons de metais alcalinos e alcalinos terrosos não afeta a adsorção de outros íons metálicos ${ }^{34}$.

A alga Spirulina foi aplicada na separação e pré-concentração de $\mathrm{Se}(\mathrm{IV})$ e $\mathrm{Se}(\mathrm{VI})$ em águas e sedimentos de rios, sendo a determinação, por espectrometria de absorção atômica com atomização eletrotérmica, realizada na suspensão do microorganismo após o processo de pré-concentração ${ }^{38}$.

Quando os biosorventes são imobilizados, tal como nos processos com resinas de troca iônica, a remoção dos metais envolve um contato convencional sólido-líquido e um processo de separação. Entretanto, diferentes métodos de imobilização estão sendo usados de forma semelhante a um aprisionamento físico dos microorganismos em materiais poliméricos, ou imobilização covalente em uma superfície sólida. O uso de poliacrilamida, sílica gel, resinas de polietilenoimina tem sido citado para imobilizar algas, bactérias e leveduras $^{33}$.

Com o objetivo de melhorar as características analíticas do procedimento, biomassas de algas têm sido, também, utilizadas em sistemas em fluxo. Neste caso, a grande afinidade entre algas e íons metálicos soma-se à eficiência dos sistemas em linha, o que melhora a velocidade analítica e aumenta a precisão do processo ${ }^{39-42}$.

A eluição dos metais com ácidos minerais é proposta em muitos procedimentos; entretanto, para que não haja destruição da biomassa, a concentração da solução ácida $\left(\mathrm{HNO}_{3}, \mathrm{HCl}\right)$ usada na liberação dos metais retidos na superfície celular deve ser baixa. Em alguns casos, para que a recuperação das espécies metálicas seja completa, a adição de um agente complexante é necessária. Por exemplo, a utilização de cianeto para realizar a eluição de $\mathrm{Hg}$ (II) e $\mathrm{HCl}$ para metilmercúrio foi aplicada com sucesso a amostras de águas do $\operatorname{mar}^{43}$. 
A capacidade apresentada pelas algas de remover rapidamente da solução os íons metálicos presentes sugere, ainda, o uso da biomassa na análise voltamétrica, como componente de eletrodos modificados. A proposta dos eletrodos modificados é aumentar a seletividade e a sensibilidade do procedimento eletroanalítico, fazendo uso de uma superfície capaz de pré-concentrar a espécie de interesse na solução. Com uma escolha adequada das condições analíticas pode ser possível otimizar as propriedades de ligação do eletrodo modificado e, portanto, sua resposta voltamétrica ${ }^{28,44}$.

\section{As fontes de matéria-prima ou o uso industrial das algas}

Cerca de 4 milhões de toneladas de algas são colhidas, anualmente, em todo o mundo, sendo os principais produtores os chineses e japoneses, seguidos pelos norte-americanos e noruegueses. As algas permitem obter produtos de baixo custo e em quantidades inesgotáveis e delas têm sido obtidos produtos imprescindíveis para a vida do homem moderno, com valores que ultrapassam alguns bilhões de dólares anuais ${ }^{45}$.

A morte das diatomáceas (crisófitas) contribui para a formação de um sedimento denominado "terra de diatomáceas", utilizado na fabricação de filtros, produtos abrasivos, cremes dentais, lixas para polimentos finos ou na indústria de cosméticos.

Muitas rodofíceas são utilizadas comercialmente como alimento para homens e para o gado, na extração do agar utilizado na fabricação de gomas, laxantes ou, ainda, como meio de cultura para bactérias. Outro aspecto de interesse econômico é a extração da carragenana, um hidrocolóide usado na produção de alimentos, principalmente nas indústrias de laticínios (iogurtes, flans, sorvetes, achocolatados) e embutidos (salsichas, presuntos), na fabricação de gelatinas e geléias, e como espessante em sopas e molhos. A carragenana é usada, também, como emulsificante e estabilizante; sua aplicação substitui o amido e a gordura na preparação de certos produtos alimentícios, com a vantagem de não ser energética, não ter cheiro, cor nem sabor ${ }^{46}$. Também são encontradas diversas aplicações em indústrias não alimentícias (tintas, têxteis, perfumes) e farmacêuticas (produtos anticoagulantes e antiinflamatórios) ${ }^{45}$.

As algas pardas são utilizadas na alimentação humana e também como fertilizantes, sendo importante fonte de ácidos algínicos, cujas propriedades coloidais são aproveitadas, por exemplo, na farmacologia em pomadas e suspensões.

Algumas algas verdes e cianofíceas apresentam, ainda, propriedades larvicidas ${ }^{47}$.

No Brasil, a região costeira compreendida entre o estado do Ceará e o norte do estado do Rio de Janeiro abriga a flora algal mais diversificada do país. No tocante à exploração de espécies com fins comerciais, a atividade de maior porte corresponde à coleta de algas vermelhas (Gracilaria e Hypnea) no litoral do nordeste, principalmente na costa entre os estados do Ceará e da Paraíba. A coleta da Gracilaria vem sendo feita desde a década de 60, por arrancamento manual ou através de mergulho livre, para fins de exportação e também para processamento no próprio país, na produção do agar. Já a Hypnea tem sido exportada como matéria prima ou já processada para a indústria de carragenana; neste caso, a biomassa é coletada em algas arribadas nas praias, e não diretamente nos locais de crescimento.

Entre o estado do Espírito Santo e a região de Búzios, RJ, uma característica marcante é a presença de vasta área coberta por fundos de algas calcárias, com teor em carbonatos superior a 90\%, estendendo-se por várias dezenas de metros de profundidade e aflorando nas marés baixas. Este banco de algas calcárias tem despertado interesse e vem sendo explorado para a produção de adubos e aditivos de rações ${ }^{48}$.
CONCLUSÃO ou o passado a firmar o presente e a premissa do futuro

É geralmente aceito que a vida no planeta teve início no mar e, até cerca de 450 milhões de anos atrás, todas as plantas eram plantas marinhas. Nos 400 milhões de anos que se seguiram, houve a evolução da flora terrestre cuja história, normalmente, é contada em termos do desenvolvimento, na morfologia e na reprodução que tornou as plantas menos dependentes da presença de água livre. Entretanto, neste processo as plantas perderam sua capacidade de viver no mar! Entre as atuais briófitas, pteridófitos e gimnospermas não há uma única espécie marinha e, entre os angiospermas - com mais de 200000 espécies adaptadas a quase todos os habitats terrestres e de águas doces - há apenas um pequeno grupo de espécies marinhas. Portanto, o mar permanece, tal como no período pré-devoniano, a província das algas, e cerca de $90 \%$ da flora marinha pertence a algum grupo de algas. Neste grupo diversificado de organismos merece destaque:

- importância bio-histórica: neste grupo há organismos, com origem há mais de 3 bilhões de anos, que são responsáveis pela estruturação da atmosfera terrestre tal como a conhecemos, possibilitando a vida sobre a superfície da Terra de todos os seres vivos aeróbicos ${ }^{49}$;

- importância ecológica: as algas são produtores primários que sustentam a vida nos mares e oceanos desempenhando, assim, um papel ecológico fundamental na manutenção destes ecossistemas e

- importância econômica: grande variedade de espécies de algas encontram uso bastante diversificado em vários países no mundo, da indústria alimentícia à de medicamentos, da cosmética à agricultura

Entretanto, é preciso potencializar os recursos científicos, tecnológicos e financeiros, coordenando os esforços nas áreas ligadas à utilização das algas e à pesquisa básica, para que as propriedades destes organismos possam ser plenamente aproveitadas, priorizando a qualidade da vida humana e respeitando os ecossistemas.

\section{AGRADECIMENTOS}

Estas palavras são fruto da convivência de M. C. Rollemberg com a Prof ${ }^{a}$. Dr ${ }^{\mathrm{a}}$. M. L. S. S. Gonçalves (Instituto Superior Técnico, Lisboa, Portugal), uma devotada e incansável observadora da vida e das suas manifestações.

\section{REFERÊNCIAS}

1. Bhattacharya, D.; Medlin, L.; Plant. Physiol. 1998, 116, 9.

2. Trainor, F.R. Em Algae as Ecological Indicators; Shubert, L. E., ed.; Academic Press: UK, 1983, p. 3.

3. Blanck, H.; Wallin, G.; Wangberg, S.; Ecotoxicol. Environ. Saf. 1984, 8, 339.

4. Maestrini, S. Y.; Bonin, D. J.; Droop, M. R. Em Ref. 2, p. 71-74.

5. Jones, A. M.; Environmental Biology, Routledge: UK, 1997, p. 57-81.

6. Boyle, T. P. Em Ref. 2, p. 237-251.

7. Chapin III, F. S.; Walter, B. H.; Hobbs, R. J.; Hooper, D. U.; Lawton, J. H.; Sala, O. E.; Tilman, D.; Science 1997, 277, 500.

8. Maestrini, S. Y.; Droop, M. R.; Bonin, D. J. Em Ref. 2, p. 133-188.

9. Rietzler, A. C.; Pasqual, C. B.; Lima, D.; Fonseca, A. L.; Espíndola, E. I. G.; Anais do 5o Encontro Brasileiro de Ecotoxicologia, Itajaí, Brasil, 1998; Taouil, A.; Valentin, Y. Y.; ibid.; Lima, D.; Pacheco, M. R.; Paschoal, C. M. R. B.; Espíndola, E. G.; ibid.

10. Fraústo da Silva, J. J. R.; Vértice 1997, 78, 18

11. Aksu, Z.; Açikel, U.; Kutsal, T.; Sep. Sci. Technol. 1999, 34, 501.

12. Mahan, C. A.; Majidi, V.; Holcombe, J. A.; Anal. Chem. 1989, 61, 624.

13. Bender, J.; Rodriguez-Eaton, S.; Ekanemesang, U. M.; Phillips, P.; Appl. Environ. Microbiol. 1994, 60, 2311. 
14. Cervantes, C.; Gutierrez-Corona, F.; FEMS Microbiol. Rev. 1994, 14, 121

15. Crist, R. H.; Martin, J. R.; Carr, D.; Watson, J. R.; Clarke, H. J.; Crist, D. R.; Environ. Sci. Technol. 1994, 28, 1859.

16. Volesky, B.; Biosorption of Heavy Metals, CRC Press: Boca Raton, FL, 1990, p. 173-198.

17. Garnham, G. W.; Codd, G. A.; Gadd, G. M.; Appl. Microbiol. Biotechnol. 1993, 39, 666 .

18. Leusch, A.; Holan, Z. R.; Volesky, B.; J. Chem. Technol. Biotechnol. 1995, 62, 279.

19. Chu, K. H.; Hashim, M. A.; Phang, S. M.; Samuel, V. B.; Water Sci. Technol. 1997, 35, 115.

20. Gupta, V. K.; Shrivastava, A. K.; Jain, N.; Water Res. 2001, 35, 4079.

21. Groudeva, V. I.; Groudeva, S. N.; Doycheva, A. S.; Int. J. Miner. Process. 2001, 62, 293.

22. Pollumaa, L.; Maloveryan, A.; Trapido, M.; Sillak, H.; Kahru, A.; Altern Lab. Anim. 2001, 29, 259.

23. Kuritz, T.; Wolk, C. P.; Appl. Environ. Microbiol. 1995, 61, 234.

24. Kapoor, A.; Viraraghavan, T.; Water Res. 1998, 32, 1968.

25. Yan, G.; Viraraghavan, T.; Bioresour. Technol. 2001, 78, 243.

26. Williams J. P.; Pure Appl. Chem. 1983, 55, 35.

27. Wood, J. M.; Wang, H. K. Em Chemical Processes in Lakes, Strategies for Microbial Resistance to Heavy Metals; Stumm, W.; ed.; WileyInterscience: USA, 1985, p. 81.

28. Cid, A.; Herrero, C.; Enrique, T.; Abalde, J.; Aquat. Toxicol. 1995, 31, 165

29. Crist, R. H.; Oberholser, K.; Shank, N.; Nguyen, M.; Environ. Sci. Technol. 1981, 15, 1212

30. Gardea-Torresdey, J. L.; Becher-Hapak, M. K.; Hosea, J. M.; Darnall, D. W.; Environ. Sci. Technol. 1990, 24, 1372.
31. Hao, Y.; Zhao, Y.; Ramelow, G. J.; J. Environ. Sci. Health 1994, A29, 2235.

32. Rollemberg, M. C.; Simões Gonçalves, M. L. S.; Correia dos Santos, M. M.; Botelho, M. J.; Bioelectr. Bioenerg. 1998, 48, 61.

33. Godlewska-Zylkiewicz, B.; Crit. Rev. Anal. Chem. 2001, 31, 175.

34. Mahan, C. A.; Holcombe, J. A.; Anal. Chem. 1992, 64, 1933.

35. Shengjun, M.; Holcombe, J. A.; Talanta 1991, 38, 503.

36. Magdi, V.; Holcombe, J. A.; J. Anal. At. Spectrom. 1989, 4, 439

37. Romero-Gonzalez, M. E.; Williams, C. J.; Gardiner, P. H. E.; J. Anal. At. Spectrom. 2000, 15, 1009.

38. Shunxin, L.; Shahua, Q.; Ganquan, H.; Fei, H.; Fresenius J. Anal. Chem. 1999, 365, 465.

39. Singh, R.; Prasqad, B. B.; Process Biochem. 2000, 35, 897.

40. Hashim, M. A.; Tan, H. N.; Chu, K. H.; Sep. Purif. Technol. 2000, 19, 39.

41. Darnall, D. W.; Greene, B.; Hosea, M.; Macpherson, R. A.; Henzl, M.; Alexander, M. D. Em Trace Metal Removal from Aqueous Solutions; Thompson, R., ed.; Royal Society of Chemistry: UK, 1986, p. 1.

42. Volesky, B.; FEMS Microbiol. Rev. 1994, 14, 291.

43. Perez-Corona, T.; Madrid-Albarran, Y.; Beceiro, E.; Camara, C.; Spectrochim. Acta, Part B 1998, 53, 321 .

44. Gardea-Torresdey, J.; Darnall, D.; Wang, J.; Anal. Chem. 1988, 60, 72.

45. Armisen, R.; J. Appl. Phycol. 1995, 7, 231.

46. http://www.usp.br/agen/rede335.htm, acessada em Setembro 2002

47. Oliveira, J. C.; Seminário Comett - Cosmectotecnia dos Produtos Marinhos, Lisboa, Portugal, 1992.

48. http://www.bdt.fat.org.br, acessada em Janeiro 2002.

49. Duve, C.; Sci. Amer. 1996, 274, 50. 